\title{
INTRODUCTION: WORDS AND IMAGES
}

Ours is a crowded symbolic universe. During our daily movements through urban infrastructures, we are bombarded with screens full of words and images that are aimed at convincing us to buy something, or vote for someone, or give our attention to a certain message. How do different types of signs affect us in different ways, and how might poetics involve a particular negotiation of this press of the symbolic? In Charles Sanders Peirce's semiotics, the Symbolic signifier, such as the word, has an arbitrary social relation to its signified meaning. The Iconic signifier, such as an image or painting, on the other hand, has a more universal quality, in that its form has a physical relation to the meaning that it signifies. Yet aesthetics complicates this semiotics. Literary texts compose fictional or poetic representations verbal images of characters, narrative events, or representations of places and material objects, from the coherent semantic chaining of the arbitrary symbolic word sign. In condemning poetry, Plato argued there was no place for poetry in the Republic because poets are rhetoricians who pass off imaginative projections as the truth. Poets use words to forge images which in turn dangerously excite the imagination and the emotions. Yet if Plato condemns poetry for seeking to form images of words, for Socrates it is also the case that it is the particular quality of writing to dangerously fix words as images. In a passage from the Phaedrus, the god Theuth claims to the King of Egypt, Thamus, that writing will be a phamarkon to the minds of the people, making them remember better, and know more. This remedy, answers Thamus, is really a drug that will render people unable to think and remember without its magical and poisonous qualities. In Socrates's telling, by extending and diverting the integration of communication and bodily existence, the artificial prosthetic support of writing will render the human organism dependent on or addicted to images, therein "going against natural life" (Derrida 1981: 100).

This positioning of words and images as somehow dangerously, or uselessly, outside the body or the things of the world has a long tradition. It is an aphoristic commonplace that words and images are typified or 
constituted by an ineffectual absence or impotence. The sentiment of the Latin phrase Res, non verba ("Deeds speak louder than words") is similarly

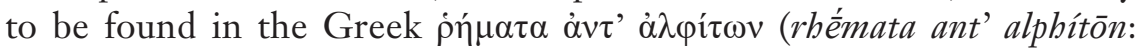
"fine words butter no parsnips"). Yet if words are ineffectual or lacking, images often also involve more sinister or entrapping qualities, a likeness that denotes a ghostliness or semblance stripped of presence. The Latin imago, from Proto-Indo-European heym- ("to imitate"), is cognate with the Sanskrit यम (yáma, "pair, twin"), indicating the far-reaching etymological roots of the image's uncanny doubling effects. In Jacques Lacan's triptych of psychoanalytic terms, Real, Symbolic and Imaginary, the Imaginary denotes the phase of narcissistic and specular identification, or "mirror stage," by which the human subject comes into being at the end of infancy by forming an alienating body image. In offering reality to us, as if proffering a gift, the regime of the image has been read as seductive, entrapping, or even as representing a kind of nakedness. If the magical transformation of Pygmalion's ivory sculpture into living human flesh from Ovid's tale perhaps allegorizes the continual transactional relation of images and reality, it is also the case that Ovid's fabula of supernatural intervention forestalls the 150 dangerous and paralysing arousal of Pygmalion's desire by the image. W. T. J. Mitchell argues that the desire of the image is to petrify its spectator, to still the observer by its own specular excesses so that the stasis of its own lifeless reduplication of reality is impressed upon the living flesh. Writing on the cinema, for Fredric Jameson, "The visual is essentially pornographic, which is to say that it has its end in rapt, mindless fascination" (1992:1). For Jameson, the apotropaic defence frequently set against the nakedness of the image by western society is to vie images with language - and thus the dialectical tension between these two modes of representation runs deep across western culture.

The recurrent modern suspicion of images perhaps echoes a disparaging iconoclasm embedded in the Mosaic religions and cultures at least since the Levitical injunction on graven images. From the seventh-century outbreak of Byzantine iconoclasm to the early modern Puritan tendency to whitewash Catholic frescos and behead sculptures of saints, sporadic eruptions of iconoclasm speak to the discomfiting power of images. A similar impulsion lies behind the March 2001 destruction of rock-cut Buddha reliefs in the Bamiyan Valley in Afghanistan by the Taliban, and ISIL's destruction of cultural heritage sites such as ancient Assyrian city Nimrud, in present day Iraq, bulldozed between late 2014-early 2015, and Palmyra in present day Syria, blown up in May 2015. Often instances of iconoclasm are impelled 
by, or seek to reorient, disarming transformations in the dialectic of word and image. Take early modern Puritanism. In the 1540s the intricate and pious medieval stone work of the Lady Chapel of Ely Cathedral was "systematically defaced by iconoclastic hammers" (O'Connell 2000: 3). This Reformation violence, directed at the visual representation of piety, was the extreme expression of the Protestant iconoclasm whose faith itself was vitally derived of and circulated by the printed word. Pitting itself as countervailing project to expansive Renaissance visuality, the fear of the "idolatrous eye," and the debased sense of the imagistic at the heart of antiCatholicism, was dependent upon a newly resurgent faith in the written circulation of knowledge, piety and awe. For Marshall McLuhan, the era of print established a culture of the word, and the subsequent reorganization of the human sensorium around typography - which McLuhan felt was being overturned at his time of writing by electronic media. Puritan violence in this understanding responded to the transition between a cultural period in which images dominated, to a new era of the word.

It is likely due to the media technological shifts of late modernity that the dialectic of words and images similarly continues to unfurl. A trace of anti-representational iconoclastic violence is perhaps to be found in the stress Gilles Deleuze places on the violent, unnatural and shocking character of his philosophy. Deleuze counterpoises his own anti-representational philosophy to the stupefying Cartesian "image of thought" (2004: 167-8). Deleuze writes, "Everybody' knows very well that in fact men think rarely, and more often under the impulse of a shock than in the excitement of a taste for thinking" (2004: 168). If Deleuze's impulsive shocks undo the thoughtlessness of Cartesian images, Guy Debord explicitly links the thoughtlessness of images to capitalism: "The whole life of those societies in which modern conditions of production prevail presents itself as an immense accumulation of spectacles. All that once was directly lived has become mere representation" (1995: 12). Each perhaps intuits a philosophy of the electronic era that McLuhan describes, and seeks to draw out the political import of the regime of images. In a yet more contemporary intervention, Marcel O'Gorman suggests the tension between words and images is no longer sustainable in the digital era, now that images are archived and circulated in the linguistics of digital code. Digital images, as Hito Steyerl observes, are "coded as pulses of light or magnetic charges or long lines of seemingly random letters" (2017: 68). As data piles up, vision "is replaced by filtering, decrypting, and pattern recognition" (Steyerl 2017: 47). This means our lives and eventual deaths are anticipated and ultimately 
survived by data. "Technological being," as O'Gorman describes, involves the experience of "necromedia," in which digitally coded medical and security images circulate in the world before we do (in the form of in utero ultrasound), will be disseminated in multiple locations and contexts while we are alive, and will remain in databases and media archives long after we die (O'Gorman 2015: 10-11).

Yet if word-images can alienate or stupefy, in Lacan's and Deleuze's terms, and currently entangle human existence with an archival trace that will far exceed our own flesh being, they can perhaps also spur political action. "I, too, dislike it," Marianne Moore writes of poetry, "Reading it, however, with a perfect contempt for it, one discovers in / it, after all, a place for the genuine." If the pile-up of the third person neuter pronoun, and the awkward enjambment of "in / it" might seems to render syntactically the unlikeability of poetry, as Ben Lerner notes (2016: 4), it is also the case that Moore reserves a zone of hope for the "genuine" on the other side of "contempt." Writing of the public role of the poet during the Northern Ireland conflict, Seamus Heaney speaks of the need for "images and symbols adequate to our predicament" (1980: 56). Wallace Stevens similarly proposes

152 that poetry constitutes "the imagination pressing back against the pressure of reality" (1951: 36). Images can be worthy responses, these poets attest, if the imagination that they foster furthers active engagement with the troubles that afflict us.

How might these understandings of words and images engage with the catastrophic contemporary situation of climate breakdown? What might Moore, Heaney and Stevens seem to suggest concerning the role of words and images in negotiating the Anthropocene, including the twenty-four Earth systems parameters currently under severe threat (in four instances their critical thresholds already exceeded) due to anthropogenic intervention (Bonneuil and Fressoz 2016)? Robert Macfarlane writes of the work of ecocriticism as seeking to describe a landscape or an ecology, to recognise its value, and perhaps in so doing to lessen the chance of its destruction (2015: 27). Ecocriticism in this telling involves a rejuvenated faith or hope in the work of the image. Yet, as the iconoclasts might advise, this is a fraught exercise. If the image itself is seductive, one of the effects of the plethora of contemporary capitalist visual cultures might seem to be that of securing business as usual, rendering ecological destruction unseeable, or swamped by other spectacles. The world lurches towards total systems breakdown, but the "distribution of the sensible," in Jacques Rancière's words, remains undisturbed. "Love is invisible. War is invisible. Capital 
is invisible," states an anonymous voice from Steyerl's film art piece How Not to Be Seen: A Fucking Didactic Educational .MOV File (2013). Also obscured by the backdrop of our contemporary word and image overload are the "sacrifice zones" (Klein 2014: 169-70) that capitalist extraction and production have created, from Indonesia's six million hectares of palm oil plantations, the estimated one hundred million tons of plastic debris that constitute the Pacific and Atlantic garbage patches (Farrier 2019), and the GMO soy farms situated on clear-cut Amazon rainforest that expedite the west's desire for cheap meat by turning perhaps the most biodiverse place in the world into pig shit. "Words make worlds," Steyerl writes. "They can destroy them as well" (2017: 128). We stumble at the brink irrevocable catastrophe, and perhaps for the first time the very biomatter of the Earth needs the urgent transformation of our word-images.

So what do works and types of thought that approach the intersection of words and images from a more positive perspective look like, meaning works that are aimed at creating something new out of thinking about words and images together, rather being concerned about the damage done to any kind of purity of one or the other in isolation? Mitchell's pictorial turn and the extensive work of Krešimir Purgar are fundamental moments in this discussion. Mitchell begins his chapter called "The Pictorial Turn" from Picture Theory with a quote from literature, Don DeLillo's Americana (Mitchell 1995: 11) and Purgar argues for the development of visual studies, which takes into account both word and image, as a "medium in its own right" (Purgar 2014: 9). Yet when talking about words and images together, we can generalize and boil down two ways in which this approach is often formulated. One way is to look at the equality of internal qualities of humanity with external qualities, the other is to question the notion of equality itself as essentialist and oppressive. Both aspects of this approach seek to problematize some assumptions about both words and images, and this problematization leads to new ways of thinking of the two together.

The first approach, meaning the equality of internal and external characteristics of humanity, relates to words and images because, as pointed out above, they have been seen as part of a somehow less or diluted expression and experience of being human. One recent attempt to challenge this view takes place by seeing how humans have always been defined by the world around and outside them; this is Andy Clark's idea of the extended mind, in which certain operations of the brain are "delegated to manipulations of external media" (2011:221). Forgetting people's telephone numbers because they are now in our phones' memory, writing down a grocery list, or using 
a blackboard to help with a math problem. These are all examples of how our minds are not confined to our bodies, but are sub-contracted, at least in part, to the world around us. This link is a "two-way interaction" which creates a symbiotic system that is itself cognitive (2011:222). In other words, the individual is not isolated from its world, rather it is formed within an interactive loop with its active agents (see Willems 2017). This is what Clark calls an "active externalism" (Clark 2011: 222), one of the key features of which is that it is based on the concept of the parity principle, so that if the external task were assumed to be taking place in the head, there would be no problem assigning it to cognition (2011: 114). In other words, active externalism is not about the validity of external content, but rather about interpreting and categorizing external states and processes (Malafouris 2013: 74). Words and images are not external to humanity, nor do the thinking images pale in comparison to that of words. The images and words of the world around us can be oppressive and destructive, but they are extensions of ourselves, not separate entities which impede on the purity of human experience or action.

This approach is about equality, or parity, as Clark states. Its strength 154 lies in how its practitioners attempt to de-center the human from how it sees itself in the world. The problem with the approach is that this "equality" between things is the world is often unmarked, which means that it is a human, white, male-centered equality without even making it explicit.

The second approach mentioned above relates to questioning the idea of equality itself. For why would an oppressed group want to be equal to the foul system that is oppressing them? Equality in this sense is about control rather than freedom. Being equal is limiting; freedom is found in liberation instead.

For example, in "Perfecting Slavery" Anthony Farley says that "The dream of equality, of rights, is the disguised wish for hierarchy. The prayer for equal rights is the disguised desire for slavery" (2005: 224). Jared Sexton, who comments on this quote in Black Masculinity and the Cinema of Policing, argues that "Emancipation, in this view, is a desire bound to the dream of equality, a palliative, an opiate of the enslaved masses, that wards against the true thought of freedom and the destruction of the terms of order of a global system of slavery it requires" (2017: x). Thus rather than constructing meaning in relation to or opposite of a system, a different approach is needed altogether, as encapsulated by Cedric Robinson's call for "Only the promise of liberation, only the promise of liberation!" (Robinson and Robinson 2017: 8). 
Here is where, for example, the concept of the Anthropocene can be found to be limiting and detrimental. At its heart, it is a human-centered approach, but with the characteristics of that human left unmarked, and thus, once again, assuming it to be white, male and European. François Vergès asks what it would mean to read the Anthropocene as racial (2017: 73), concluding that to do so "will help us understand that climate change is not about human hubris, but the result of a long history of colonialism and racial capitalism and its Promethean thinking - the idea that 'Man' can invent a mechanical, technical solution to the problem" (2017: 80). What is needed instead are structural changes, and multitudes of them, which are reflective of the diversity of the world we live in. This is why Kathryn Yusoff has titled her recent book A Billion Black Antbropocenes or None (2018). Either a continual multi-pronged liberation from the idea of the Anthropocene, or move on to another form of thinking altogether.

But what would this kind of liberation of word and image look like in literature? It could look like an attempt at words or images being freed from one another, although not in the form of negation, but rather to leave their individualities behind to explore what they have in common. One example of this is Dennis Cooper's HTML GIF novel Zac's Haunted House (2015). Each chapter is a series of silent GIF images, culled from other sources and compiled in sentence and paragraph-like groups. Although some of these gifs include words, the majority of them are image-only. However, this is not just a visual image like a painting or sculpture. The images are grouped together in a way that they are seen as literature, as a text, rather than as a film or video.

We can read the "Preface" of the novel as an example. There are only two images and they are placed one on top of the other. The first shows a telegraph, with its key coming into repetitive contact with a metal plate, thus completing its current and sending a signal. The GIF underneath shows the widening yellow eyes of a human devil, with red skin and black markings, seemingly underneath a strobe light. Neither image contains any text, although the first is about the transmission of text. However, the images are connected to each other. The beat of the telegraph key mirrors the beat of the strobe light. This connection, and the placement of the images next to each other, suggests that other connections should be found. The telegraph is about messages arriving from far away. When coupled with the bottom picture, it seems that the message coming through is an evil one, meaning the devil himself. This would match the horror genre of the novel, and would suggest that one way to interpret the text is by looking for signs of evil being transmitted from another realm or world. 
Using images in this way does not negate text, but rather foregrounds certain aspects of text and supresses others. As Cooper has said in an interview about the novel:

You can actually take the stuff I don't like about fiction-the characters and the plot lines-and you can put it on the bottom, and it turns everything inside out. You see the structure first. The structure's fun and pleasurable and scary, and so you see that first, and everything that isn't interesting to me becomes the ground work. It's still there, it has to be there to work, but it's not on the surface. That's why the GIF work has been so exciting to me. It's like I'm able to do this thing I've always wanted to do, and actually get away from what these strictures that written fiction have place on you. (Stosuy and Cooper 2016)

What this quote and brief textual analysis argue is that words and images are not necessarily in a detrimental relationship to each other, nor are they intrinsically damaging to any being that is using them or being used by them. Instead, when the two are put in a tension with each other new aspects of each can come forth.

Regarding the specific content of this special section, the politics of words and images, and the way the verbal images in poetry can be used to silence that which is rendered as image is explored in Martina Domines Veliki's essay, "Visualizing Poverty in Wordsworth's Poetry." In order to reassess Wordsworth's use of tropes of the picturesque, Domines Veliki returns to New Historicist readings of poverty in three of Wordsworth's most canonical poems, "Michael," "The Old Cumberland Beggar" and "Resolution and Independence," rereading these works with the ethnographic analytical methods of the New Poverty Studies. Domines Veliki demonstrates how an aesthetics of the picturesque is central to Wordsworth's construction of images (despite Wordsworth's protestations to the contrary). Her essay explores the interplay of silencing and poetics in the unintelligible voice of the leech gatherer from whose poverty Wordsworth draws celebrated images in "Resolution and Independence." Countering largely sympathetic accounts of the leech gather in New Historicist criticism, Domines Veliki shows how this silencing is consistent with Wordsworth's Whig politics, and also the disturbing subterranean parallels of Wordsworth's positions on poverty with those of Malthus. She shows how the poetic framing of picturesque tropes in the form of verbal images herein involves a silencing of poverty - a distancing from words of the poor, and herein a delimitation of potential concern for, and political intervention into, the situation of the poverty depicted by the poetic image. 
In "Gerard Manley Hopkins and the Ecological Balance of Wildness," Mirko Starčević addresses the imaging making involved in ecological studies by looking at Hopkins' nineteenth-century poetry. Hopkins expressed his distress at the human-caused destruction of the environment, and he even set out to save the environment in his own way by capturing his diminishing surroundings in the unique beauty of his poetry. A comparison with other, earlier ecologically minded poets, such as John Clare, bring Hopkins' work into focus. The main thesis of Starčević's essay is that Hopkins addresses global ecological concerns through an intense attention to the local environment, using his poetry to forge a connection between the two.

Stipe Grgas examines the way that Don DeLillo's short story "Hammer and Sickle" creates an image of finance in the face of what Mark Fischer describes as capitalist realism, meaning a state in which capitalism has become so pervasive that no alternative can be imagined. DeLillo's strategy for using words to create his images of financialization can be found in the structure of the story. The composition is circular, meaning that the beginning and ending are connected. However, this is a connection with a difference: the narrator ends the story with images of both self-identification and naming the necessity of capitalism he lives under, thus putting capitalist realism into a literary imaginary.

In "The Status of Illustrations in Croatian Translations of Children's Classics," Smiljana Narančić Kovač takes a look at the relation between words and images from a different perspective. In her reading of children's classics translated from English into Croatian, the author focuses on the retention of the original illustrations in the new Croatian editions of the books, stressing the semantic shifts that take place in this change of context. It is shown that the use of original illustrations declined after the 1990s, in favor of producing new sets of pictures. While these new images sometimes imitate part of the original illustrations, they never interpret them as a whole. At times the meaning of the text is altered in these newly made image sets.

By fixing overlying schemata of images in a single narrative place, words can also profoundly explore historical and national identity. Exploring the novels of Albanian writer Ismail Kadare, Mariglena Meminaj and Roland Zisi's essay "The Symbolic Function of Imperial Signs and Images in the Literary Work of Ismail Kadare," locates the dense palimpsest of overlaid histories invoked by Kadare's prose. Demonstrating how Kadare moved away from the official communist aesthetic of socialist realism, Meminaj and Zisi show how Kadare created a counter-history and an alternative Albania. Employing the literary theories of Paul Ricoeur, they describe as 
"imperial signs" the densely coded imagistic references to lingering and intertwining traces and imperialist incursions upon Albanian history, be they Roman, Ottoman, fascist or communist. Fiction is significant, in their account of Kadare, because in constructing coherent narrative passages between different layers of history's palimpsest, fiction reveals (and also potentially reroutes) the negotiation of words and images that produces cultural meanings and national identities.

Here we might briefly return to the above discussion of Cooper's novel Zac's Haunted House. As discussed, in the novel it is the specific image-creating mechanism of language, and particularly metaphor, that comes to the fore. The GIFs are joined so that the tenor and vehicle of metaphor are coupled to create a new image or meaning. The difference is that Cooper's novel is a large succession of visual metaphors, one after the other: an innovative cohabitation and syntax of a familiar digital form, and thus requires a different reading skill-set. Exemplifying the emergent practices that poetics can enable, the novel forges from the shifting media environment a new way of combing words and images - and in so doing encourages in its readers a new way of reading. This is a good thing

158 since poetics as force of cognitive change can be an embedded material investigation of - and with - the ever-changing world. It is something words and images can do.

Guest editors Simon Ryle and Brian Willems

\section{WORKS CITED}

Bonneuil, Christophe and Jean-Baptiste Fressoz. 2016. The Shock of the Anthropocene: The Earth, History and Us. London: Verso.

Clark, Andy. 2011. Supersizing the Mind: Embodiment, Action and Cognitive Extension. Oxford UP.

Cooper, Dennis. 2015. Zac's Haunted House. Paris: Kiddiepunk. Web. 20 June 2019.

Debord, Guy. 1995. The Society of the Spectacle. Trans. Donald Nicholson-Smith. New York: Zone Books.

Deleuze, Gilles. 2004. Difference and Repetition. Trans. Paul Patton. London: Continuum.

Derrida, Jacques. 1981. "Plato's Pharmacy.” In: Dissemination. Trans. Barbara Johnson. Chicago: University of Chicago Press: 63-171.

Farley, Anthony. 2005. "Perfecting Slavery." Loyola University Chicago Law Journal 36: $225-256$.

Farrier, David. 2019. Anthropocene Poetics: Deep Time, Sacrifice Zones, and Extinction. Minneapolis: Minnesota University Press. 
Heaney, Seamus. 1980. "Feeling into Words," In: Preoccupations: Selected Prose, 1968 1978. New York: Farrar, Straus and Giroux: 41-60.

Jameson, Fredric. 1992. Signatures of the Visible. New York: Routledge.

Klein, Naomi. 2014. This Changes Everything: Capitalism vs. The Climate. New York: Simon and Schuster.

Lerner, Ben. 2016. The Hatred of Poetry. New York: Farrar, Strauss and Giroux.

Macfarlane, Robert. 2015. Landmarks. London: Hamish Hamilton.

Malafouris, Lambros. 2013. How Things Shape the Mind: A Theory of Material Engagement. MIT Press.

McLuhan, Marshall. 1962. The Gutenberg Galaxy: The Making of Typographic Man. Toronto: University of Toronto Press.

Mitchell, W. T. J. 1995. Picture Theory: Essays on Verbal and Visual Representation. Chicago: University of Chicago Press.

Mitchell, W. T. J. 2005. What Do Pictures Want?: The Lives and Loves of Images. Chicago: University of Chicago Press.

Moore, Marianne. 1967. "Poetry," In: Complete Poems. London: Faber and Faber: 36.

O'Connell, Michael. 2000. The Idolatrous Eye Iconoclasm and Theater in Early-Modern England. New York: Oxford University Press.

O'Gorman, Marcel. 2015. Necromedia. Minneapolis: Minnesota University Press.

Purgar, Krešimir. 2014. "Visual Studies and the Pictorial Turn: Twenty Years Later." In: Image 2: 1-10.

Rancière, Jacques. 2004. The Politics of Aesthetics: The Distribution of the Sensible. Trans. Gabriel Rockhill. London: Continuum.

Robinson, Cedric and Elizabeth Robinson. 2017. "Preface." In: Futures of Black Radicalism. Eds. Gaye Theresa Johnson and Alex Lubin. London: Verso: 1-8.

Sexton, Jared. 2017. Black Masculinity and the Cinema of Policing. Cham: Palgrave Macmillan.

Stevens, Wallace. 1951. "The Noble Rider and the Sound of Words," In: The Necessary Angel. New York: Alfred A Knopf: 1-36.

Steyerl, Hito. 2013. How Not to Be Seen: A Fucking Didactic Educational .MOV File, In: Artforum. Web. 28 June 2019.

Steyerl, Hito. 2017. Duty Free Art. New York: Verso.

Stosuy, Brandon and Dennis Cooper. 2016. "Dennis Cooper on Writing as Sculpture." In: The Creative Independent. 18 Oct 2016. Web. 26 June 2019.

Vergès, François. 20017. "Racial Capitaloscene.” In: Futures of Black Radicalism. Eds. Gaye Theresa Johnson and Alex Lubin. London: Verso: 72-82.

Willems, Brian. 2017. "Galactic Modernism: Distributed Individuality in Olaf Stapledon's Last and First Men and Star Maker." In: New Perspectives on Community and the Modernist Subject: Finite, Singular, Exposed. Eds. Paula Martin Salvan and Gerardo Rodríguez Salas. London, New York: Routledge: 146-163.

Yusoff, Katheryn. 2018. A Billion Black Anthropocenes or None. Minneapolis: University of Minnesota Press. 